REVIEW

\title{
The Advanced Trauma Life Support course: a history of its development and review of related literature
}

\section{R Carmont}

Postgrad Med J 2005;81:87-91. doi: 10.1136/pgmi.2004.021543

The origins, development, and success of the ATLS course are described with reference to the literature.

$\mathrm{S}$ ince 1978, the Advanced Trauma Life Support (ATLS) course has instructed many doctors from all over the world. Many articles have been written about the course from reviews to case reports and letters. A previous review of trauma education has already described methods of adult education. ${ }^{1}$ This article presents a further review of the current literature concentrating on the background, efficacy, and educational methods of ATLS, rather than discussion about the actual scientific content of the course itself.

\section{BACKGROUND}

The ATLS course was established after a tragic plane crash in 1976, which devastated an entire family. The pilot, an orthopaedic surgeon named James Styner, was seriously injured while his wife was killed and three of his children sustained critical injuries. He was horrified at the treatment his family received at a local hospital in rural Nebraska and decided that the established system for managing the severely injured was wrong. A group of local surgeons and physicians, the Lincoln Medical Education Foundation, together with the University of Nebraska founded local courses aiming at teaching advanced trauma life support skills. ${ }^{2}$ These courses served as a framework for the national ATLS courses adopted by the American College of Surgeons' Committee on Trauma.

The original aims of the ATLS courses were to train those doctors who do not manage trauma on a regular basis, such as rural general practitioners, in the initial management of the severely injured patient. The pilot courses were run in Aubern, Nebraska in 1977. These had expanded nationally under the auspices of the American College of Surgeons by 1980. Early reports on the implementation and evaluation of these pilot courses and the improvements in rural trauma care appeared in the literature soon afterwards. ${ }^{3}$ Improvements were also noted in the quality of trauma care apparent upon the arrival of patients at a major hospital ${ }^{5}$ and on mortality rates, using multiple logistic regression analysis. ${ }^{67}$ Additional studies suggest an improvement related to the introduction of ATLS $^{8}$ but others have failed to show significant improvement in patient outcome and assessment. ${ }^{9}$

In the late 1980s, a retrospective analysis of deaths attributable to injury reported that significant numbers could have been prevented. ${ }^{10}$ A subsequent Working Party Report from the Royal College of Surgeons, England noted the improvement in standards of care of the injured patient in the United States after the development of ATLS. ${ }^{11}$ ATLS was brought to the United Kingdom with the first course taught at the Royal College of Surgeons in 1988. By 1995, it had been taught in over 25 countries and has been shown to be an effective teaching course in both developing and developed countries. ${ }^{12}$ Today ATLS is the internationally recognised standard for the initial assessment and management of serious injury. ${ }^{13}$

\section{PARTICIPATION AND RELEVANCE}

The initial role of the course was to teach doctors working in rural situations such as general practitioners at community and small district general hospitals. Within the United Kingdom, junior doctors are encouraged to complete the course early in their career and the Royal College of Surgeons and the Faculty of Accident and Emergency Medicine both require it for college membership examinations. It has been suggested that it should be mandatory for all doctors in training. ${ }^{14}$

Trainees themselves have been reported to be very favourable towards ATLS. By 1996, 97\% of respondents to a questionnaire survey of senior house officers regarded ATLS as useful for preparation for the FRCS examination. ${ }^{15}$ In a separate study $83 \%$ trainees considered it essential for practising their proposed specialty. Most considered it an important advantage for their curriculum vitae and $94 \%$ thought that ATLS saved lives. ${ }^{16}$

By 1995, 220000 doctors had been trained on 1100 courses $^{17}$ and currently demand for courses exceeds availability. Reports surveying doctors working as residents in emergency departments have argued that there has been inadequate provision of places on courses for this level of training. ${ }^{18}$ Comments have been made upon the increased participation of emergency medicine specialists on ATLS courses. It has been argued that these doctors are more likely to manage major trauma on a regular basis, and so could undertake a shorter course compared with that provided for other specialties. ${ }^{19}$ Clearly this would have an impact upon course standardisation. Rural doctors have shown a greater level of improvement from ATLS course participation and therefore it has been suggested that greater efforts should be made to increase rural doctor participation. ${ }^{20}$ Similarly doctors from nonsurgical medical specialties treat a significant number of trauma events after ATLS course participation. ${ }^{21}$ 
The spread of ATLS doctrine has not always passed smoothly. A survey of American general surgeons in 1995 disclosing that although one third of respondents had completed the course within the past four years, only $40 \%$ of those who considered themselves to be extremely confident in trauma resuscitation had completed ATLS. ${ }^{22}$ A common comment is that the protocol driven ATLS course prevents doctors thinking through problems directed by traditional medical teaching, although medical school education is currently moving towards problem based learning. Recent questionnaires completed by UK surgeons showed that ATLS was now considered as being essential or of some value. $^{23}$

After introduction to the UK, places on ATLS courses were preferentially offered to senior medical staff. Early providers and instructors were quick to design local courses teaching ATLS principles to junior and comparatively inexperienced staff and encouraged others to do the same. ${ }^{24}$

Currently within the UK, the ATLS course is only available to doctors at or senior to the senior house officer grade. Given the limited availability of course places, junior doctors may have moved on by the time a course becomes available reducing maximal benefit. ATLS courses prepare medical students more effectively for managing trauma patients when judged by trauma simulation scenarios and authors have suggested that the ATLS training should be part of the medical school curriculum. ${ }^{25} 26$ Although this would be expensive, the cost must be off set against future training costs, time off work, and better patient management as a junior doctor. New senior house officers have been shown to make a greater improvement in trauma management testing after an ATLS course when compared with accident and emergency induction courses. ${ }^{27}$

Although the course is for the training of doctors primarily, nurses, ${ }^{28}$ paramedics, firemen, and armed police officers have shown a significant improvement in knowledge after participating in the course as observers. Some of these have gained exceptionally high marks in the formally assessed sections of the course despite no previously recognised medical training. This benefit is due to the structured nature of the course, the teaching skills used, and the motivation of the participants themselves. Educationalists appreciate that if the motivation to learn is self generated by the participant, learning will be more meaningful and the resultant change longer lasting. ${ }^{29}$

Instruction in the United Kingdom, is provided by doctors who have excelled as providers and are subsequently trained at the Royal College of Surgeons in London. Many of these doctors will have shown an aptitude for teaching on their provider course, but will have no formal educational qualifications. In some cases their personal educational experience may have been tarnished by previous teaching at medical school. However, the skills of the educator on the instructor course rapidly increase the development of instructional abilities. A questionnaire evaluation of participants has shown increased confidence in postgraduate medical education after the instructor course. ${ }^{30}$ The bulk of the educational material on the instructors' course is provided in the form of a manual, ${ }^{31}$ which provides teaching advice in section III "Teaching how to teach". This provides general teaching information about lecturing, running group skill and practical stations, and the final assessment. This is similar in nature to the core educational material in The Generic Instructors Manual ${ }^{32}$ of The Advanced Cardiac Life Support Course (ACLS). The theoretical perspectives of the Generic Instructors Course have been reviewed and this educational model has been recommended for further general medical education. ${ }^{33}$

The Advanced Life Support Group, Manchester has produced a specialist pocket guide for teaching. These educational principles are then readily available to medical teachers not already involved in instructing on courses. ${ }^{34}$

\section{COURSE COMPOSITION}

The ATLS course aims to provide one safe method for the management of severe trauma and to set standards of resuscitation of the trauma victim. Previous trauma education had been limited to didactic lectures and use of the preceptor technique. One of the initial aims of ATLS was to provide practical education with hands on techniques for the management of trauma ${ }^{5}$ in a manner similar to those used on the well established ACLS course.

The course is intensive, normally consisting of two to three days' duration, beginning with registration, introductory sessions, and lectures. The first two days are comprised of lectures, demonstrations, and discussion of initial assessment and resuscitation, followed by more formal lectures such as airway management, skill stations such as radiological interpretation and practical skill stations such as chest drain insertion.

The bulk of factual information is provided in a 444 page manual $^{17}$ now in its sixth edition, supplied to candidates about six weeks before the course. A common reason for candidates to fail to complete the course is due to lack of prior preparation and inadequate reading. The manual may seem somewhat daunting to doctors who have already participated in the ACLS course, which has a smaller 138 page manual. ${ }^{35}$ Senior medical students taught on combined ACLS/ATLS provider course had similar completion rates; 95\% compared with $92 \%{ }^{36}$ Reinforcement of the factual information within the manual occurs during the formal lectures and skill stations of the course.

Lectures are given to a standard format based upon a three part approach facilitating the teaching and learning process. ${ }^{37}$ This set, dialogue, and closure method enables the instructor to revise the factual content of the manual and allows time for personal "associative" anecdotes and innovation to emphasise particular points. ${ }^{38}$ Instructors may add photographic slides although the core text may not be changed. Such creativity is thought to be advantageous in medical education. ${ }^{39}$ Finally, there is opportunity for questions at the end of the lecture. The educational value of the ATLS lectures has been shown with students scoring higher in a postlecture series test compared with controls. ${ }^{40}$

Skill stations allow further attention to particular points of ATLS practice, for example, shock management, radiological interpretation. They also permit opportunity for small group discussion, encourage active participation, making learning successful and enjoyable. ${ }^{41}$ The small groups allow personal attention to participants to meet their requirements with a high instructor to candidate ratio, for example, 1:3, thus permitting close attention to individual learning needs.

Instructors are taught to use a modified version of a five step method for teaching clinical skills ${ }^{42}$ incorporating overview, silent demonstration, instructor described demonstration, student described demonstration, and student demonstration. The silent run through provides the candidate with strong visual images, which provides a mental practice on which to base further learning. ${ }^{38}{ }^{43}$ However, the silent run through does not improve skill acquisition for radiological interpretation. ${ }^{44}$

Criticisms have been raised regarding specialist skill instruction. ${ }^{45}$ Care is taken within the session to ensure the skill is taught according to the ATLS method for all candidates, without offending highly experienced doctors who may perform the skills on a daily basis.

The practical skill stations are made as realistic as possible. Early American courses used live anaesthetised animals for procedures, for example, chest drain insertion and 
pericardiocentesis. ${ }^{3}$ UK legislation prevents this practice, however the use of cadaveric animals has been adopted as an educational tool ${ }^{46}$ providing a balance of realistic simulation and practicality. These skill stations have been revised and have been performed on artificial human patient simulators, which students found to be favourable ${ }^{47}$ and by computer simulation. ${ }^{48}$ They have even been practised in micro-gravity by NASA. ${ }^{49}$

After small group discussion of triage, participants have shown improved prioritisation ability in multiple patient simulations $^{50}$ and conflict. ${ }^{51}{ }^{52}$

\section{PARTICIPANT/PROVIDER ASSESSMENT}

A multiple choice questions (MCQ) pre-test paper is sent to candidates with the manual. This provides course participants with increased motivation, enthusiasm, and an example of the expected standard of knowledge ${ }^{5354}$ and also highlights those candidates who may not have prepared properly or may need to have special attention. Quantitative assessment of knowledge is examined by a MCQ on the final morning of the course and a pass mark of 32 of 40 maintains high standards.

The MCQ examination for the ATLS course is deemed so discriminatory regarding trauma management decisions, that it has been used recently to evaluate trauma education in medical students at the University of Toronto. ${ }^{55}$ Although MCQs have been shown to be the least preferred method of assessment by students, ${ }^{56}$ they have been shown to be more efficient, reliable, and valid than patient management problems in the assessment of clinical competence. ${ }^{57} 58$

Throughout the course participants are continually objectively assessed, with instructors taking note of questions asked and answered, and group dynamics together with skill and aptitude at the skill stations.

The course culminates in a final assessment of the resuscitation of a multiply injured patient. This "role play", termed a moulage, allows instructors to gain an impression of a candidate's degree of competence. This is based upon the ATLS philosophy of treating the greatest threat to life first, with rapid assessment and resuscitation of the patient according to priority. This practice was initially thought to be controversial as it contradicted the established medical wisdom of the need to take a history and examine the patient leading to a differential diagnosis. ${ }^{59}$ The improved moulage performance of residents, before and after an ATLS course has shown that ATLS teaching methods are effective. ${ }^{6061}$

During the later stages of the course experienced participants are introduced to the concept of critiquing another participant's performance. This allows opportunities to reinforce instruction and identify participants with an aptitude for teaching. Such reflection has been advocated in professional education. ${ }^{62}$

Non-formal assessment of participants is performed during breaks in the course and through mentoring sessions. During these periods, time is specifically set aside to permit one to one contact between participant and instructor. Discussion permits opportunity for individual learning needs to be addressed. Participant's strong points can be praised and the instructor can identify the participant's weaknesses and areas of concern. ${ }^{63}$

\section{RE-CERTIFICATION}

After completion of the ATLS course successful participants are provided with a certificate, which remains valid for four years. It is well appreciated that without regular practice ATLS skills deteriorate as time progresses after the course. Authors report a deterioration of knowledge by six months after the course however the important principles are retained for some six years. ${ }^{64}$ Those doctors involved in managing trauma on a regular basis, for example, surgeons, have been shown to retain their knowledge for longer when compared with physicians. Physicians tend to have lost a significant amount of acquired cognitive knowledge by 3.5 years. ${ }^{65}$ It has been suggested that trauma volume influences retention of skills ${ }^{66}$ but sex, age, and practice specialty do not affect attrition rate. ${ }^{67}$ Re-certification is required to maintain accreditation. Cognitive deterioration was not shown to improve after the last course revision. ${ }^{68}$

Instructors are required to teach on two courses a year to maintain their accreditation. This permits the maintenance of resuscitation skills and knowledge together with teaching abilities. The retention of knowledge is further aided by the fact that most instructors manage trauma on a regular basis and use the skills taught on the instructor course on teaching medical students and residents. Studies have shown that both providers and instructors lose ATLS skills over time but cognitive knowledge is lost quicker than practical skills. ${ }^{69}$

\section{COURSE EVALUATION}

Since the initial course in 1977 evaluation has been an essential part of ATLS with course participants completing an evaluation questionnaire before the course closure. This is personal to individual teaching centres and covers the lectures, skill stations, practical demonstrations, and discussions on a five point scale. Environmental and domestic points are also evaluated to ensure an optimal learning atmosphere.

Instructors carefully scrutinise comments looking for praise or areas for improvement after varying presentations of the standard lectures. So far there has been little published on ATLS course evaluation.

\section{COURSE REVISION/UPDATE}

As medical science progresses, investigation and treatment methods are evaluated and management strategies are revised. This is similarly true for the ATLS course, after publication of the sixth edition of the manual in 1997 and the seventh in the near future.

Teaching techniques as well as the scientific content have been updated. Previous course improvements in 1997 have emphasised interactivity between the student and the educational process. Didactic lectures were shortened and more focused discussions were used to encourage learning. Skill stations were redesigned around case scenarios to encourage the cognitive process and performance of the psychomotor skill, ${ }^{70}$ for example, the step-wise assessment of airway management with cervical spine control after a motor vehicle accident. In a randomised control trial, doctors educated in a small group session performed better on patient management than a didactically lectured cohort. ${ }^{71}{ }^{72}$

Such improvements have been evaluated and participants have been shown to improve clinical trauma management skills without the loss of cognitive performance. ${ }^{73}$ This improvement was thought to be attributable to interactive teaching, adult education principles, opportunities for discussion, provision of feedback, and stimulation for self learning. The skill improvement was maintained after two years compared with previous courses, however deterioration of cognitive knowledge remained similar. ${ }^{69}$

Future educational developments include changes of emphasis within current management pathways and increased involvement of the student in the educational process at skill stations. Medical changes will also feature in the new manual including the criteria for the lateral cervical spine radiograph and the new concept of the focused abdominal sonogram for trauma (FAST) ultrasound examination. ${ }^{6}$ 


\section{CONCLUSION}

The ATLS course has developed into a global resuscitation programme with confirmed results in terms of both teaching and trauma outcome. The course's methods have stood up to significant scientific scrutiny over the past 25 years. Such continual critical appraisal ensures modernisation and improvement both medically and educationally. The new scientific and educational content of the updated manual are eagerly awaited.

\section{ACKNOWLEDGEMENTS}

The author would like to thank Dr Peter Oakley for his assistance with the preparation of this manuscript together with the outstanding support and assistance from the staff of The North Staffordshire Medical Institute Library and the Department of Medical Illustration North Staffordshire Royal Infirmary.

Funding: none.

Conflicts of interest: none declared.

The author is associated with the Centre for Primary Health Care Studies, The University of Warwick.

\section{REFERENCES}

1 Carley S, Driscoll P. Trauma education. Resuscitation 2001;48:47-56.

2 Collicott PE. Advanced Trauma Life Support (ATLS); past, present, future16th Stone Lecture, American Trauma Society. J Trauma 1992;33:749-53.

3 Sims JK. Advanced Trauma Life Support Laboratory: pilot implementation and evaluation. JACEP 1979;8:150-3.

4 Collicott PE. Advanced Trauma Life Support Course, an improvement in rural rrauma care. Nebr Med J 1979;Sep:279-80.

5 Collicott PE, Hughes I. Training in advanced trauma life support. JAMA 1980;243: 1156-9.

6 Ali J, Adam R, Butler AK, et al. Trauma outcome improves following the advanced trauma life support program in a developing country. J Trauma 1993;34:890-8.

7 Adam R, Stedman M, Winn J, et al. Improving trauma care in Trinidad and Tobage. West Indian Med J 1994;43:36-8.

8 Calleary JG, El-Nazir AK, El-Sadig O, et al. Advanced trauma life support principles: an audit of their application in a rural trauma centre. Ir J Med Sci $1999 ; 168: 93-8$

9 Vestrup JA, Stormorken A, Wood V. Impact of Advanced Trauma Life Support training on early trauma management. Am J Surg 1988;155:705-7.

10 Anderson ID, Woodford M, De Dombal FT, et al. Retropsective study of 1000 deaths from injury in England and Wales. BMJ 1988;296:1305-8.

11 Royal College of Surgeons. Report of the Working Party on the management of patients with major injuries. London: Royal College Surgeons, 1988:32.

12 Ali J, Adam R, Stedman M, et al. Cognitive and attitudinal impact of the Advanced Trauma Life Support Program in a developing country. J Trauma 1994;36:695-702.

13 Gwinnutt CL, Driscoll PA. Advanced Trauma Life Support. Eur J Anaesth 1995; 13:95-101.

14 Ben-Abraham R, Weinbroum AA, Kluger $Y$, et al. Pediatricians and the advanced trauma life support (ATLS): time for reconsideration. Isr Med Assoc J 2000;2:513-16.

15 Graham CA, Sinclair MT. A survey of advanced trauma life support training for trainees in acute surgical specialities. Injury 1996;27:631-4.

16 Campbell B, Heal J, Evans S, et al. What do trainees think about advanced trauma life support (ATLS)? Ann R Coll Surg Engl 2000;82:263-7.

17 American College of Surgeons. Advanced Trauma Life Support (ATLS) student manual, 6th ed. Chicago, IL: American College of Surgeons, 1997.

18 Hughes G, Price A. ATLS: are we training the wrong people? Aust N Z J Surg 1999;69:567-8.

19 Richards JR, Panacek EA, Brofeldt BT. Advanced Trauma Life Support (ATLS) necessary for emergency physicians? Eur J Emerg Med Sep, 2000;7:207-10.

20 Ben-Abraham R, Stein $M$, Shemer J, et al. Advanced trauma life support (ATLS) courses: should training be refocused towards rural physicians. Eur J Emerg Med 1999;6:111-14.

21 Ben-Abraham R, Stein $M$, Kluger $Y$, et al. The impact of advanced trauma life support course on graduates with a non-surgical medical background. Eur J Emerg Med 1997;4:11-14.

22 Esposito TJ, Kuby A, Unfred C, et al. General surgeons and the Advanced Trauma Life Support Course: is it time to refocus? J Trauma 1995;39:929-34.

23 Brooks A, Williams J, Butcher W, et al. General surgeons and trauma. A questionnaire survey of general surgeons in training in ATLS and involvement in the trauma team. Injury 2003;34:484-6.

24 Williams $\mathrm{L}$, Muwnaga $\mathrm{CL}$, Worlock $\mathrm{PH}$, et al. Teaching trauma management in the accident and emergency department. Arch Emerg Med 1991;8:205-9.

25 Ali J, Howard M. The advanced trauma life support course for senior medical students. Can J Surg 1992;35:541-5.

26 Ali J, Cohen RJ, Gana TJ, et al. Effect of the Advanced Trauma Life Support Program on medical students' performance in simulated trauma patient management. J Trauma 1998;44:588-91
27 Gautam V, Heyworth J. A method to measure the value of formal training in trauma management:comparison between ATLS and induction courses. Injury 1995;26:253-5.

28 Gautam V, Heyworth J. The value of the abbreviated ATLS course for accident and emergency nurses. Accid Emerg Nurs 1994;2:100-2.

29 Darkenwald GG, Merriam SB. Adult education foundations of practice. New York: Harper, Row, 1982

30 Moss GD. Advanced Trauma Life Support instructor training in the UK: an evaluation. Postgrad Med J 1998;14:220-4.

31 American College of Surgeons. Advanced Trauma Life Support (ATLS) instructor manual, 6th ed. Chicago, IL: American College of Surgeons, 1997.

32 Resuscitation Council (UK). Generic Instructor Course, Advanced Life Support instructor manual. London: Resuscitation Council (UK), 2001.

33 Davis $\mathrm{M}$, Conaghan P. An examination of the theoretical perspectives underlying the ALSG generic instructors course. Med Teach 2002;24:85-9.

34 Mackway-Jones K, Walker M. Pocket guide to teaching for medical instructors. London: BMJ Books, 1997

35 Resuscitation Council (UK). Advanced Life Support (ALS) Course provider manual, 4th ed. London: Resuscitation Council (UK), 2000.

36 Mehne PR, Allison EJ Jr, Williamson JE, et al. A required, combined ACLS/ ATLS provider course for senior medical students at East Caroline University Ann Emerg Med Jun, 1987; 16:666-8.

37 Joyce B, Weil M. Models of teaching, 3rd ed. New Jersey: Prentice Hall, 1972.

38 Gagne RM. The conditions of learning and theory of instruction. New York: Holt, Rinehart and Winston, 1985.

39 Handfield-Jones R, Nasmith L. Creativity in medical education: the use of innovative techniques in clinical teaching. Med Teach 1993;15:3-11.

40 Papp KK, Miller FB. A required trauma lecture series for junior medical students. J Trauma 1995;38:2-4.

41 Abercrombie MLJ. The anatomy of judgement. London: Penguin, 1960.

42 George JH, Doto FX. A simple five-step method for teaching clinical skills. Fam Med 2001;33:577-8.

43 Ausubel DA. Educational psychology: a cognitive view. New York: Holt, Rinehart and Winston, 1968

44 Murdoch Eaton D, Cottrell D. Structured teaching methods enhance skill acquisition but not problem solving abilities: an evaluation of the "silent run through". Med Educ 1999;33:19-23.

45 Bennett JR, Bodernham AR, Berridge JC. Advanced Trauma Life Support: a time for reappraisal. Anaesthesia 1992;47:798-800.

46 Eaton BD, Messent DO, Haywood IR. Animal cadaveric models for advanced life support training. Ann R Coll Surg Engl 1990;72:135-9.

47 Block EF, Lottenberg L, Flint L, et al. Use of a human patient simulator for the advanced trauma life support course. Am Surg 2002;68:648-51.

48 Liu A, Kaufman C, Ritchie T. A computer-based simulator for diagnostic peritoneal lavage. Stud Health Technol Inform 2001;81:279-85.

49 Campbell MR, Billica RD, Johnston SL 3rd, et al. erformance of advanced trauma life support procedures in microgravity. Aviat Space Environ Med 2002;73:907-12

50 Williams MJ, Lockey AS, Culshaw MC. Improved trauma management with advanced life support (ATLS) training. J Accid Emerg Med 1997;14:81-3.

51 Walsh DP, Lammert GR, Devoll J. The effectiveness of the advanced trauma life support system in a mass casualty situation by non-trauma-experienced physicians: Grenada 1983. J Emerg Med 1989;7:175-80.

52 Greenslade GL, Taylor RH. Advanced Trauma Life Support aboard RFA Argus. J R Nav Med Serv 1992;78:23-6.

53 Rodin AE, Carlson PG, Barton JC. The pre-test as a pre-instructional strategy in continuing medical education. J Med Educ 1978;53:208-9.

54 Hill DA. Role of pre-test in the progressive assessment of medical students. Aust N Z J Surg 1992:62:743-6.

55 Ali J. The trauma evaluation and management (TEAM) teaching module: its role for senior medical students in Canada. Can J Surg 2003;46:99-102.

56 Hill DA, Guinea Al, McCarthy WH. Formative assessment: a student perspective. Med Educ 1994;28:394-9.

57 Norcini JJ, Swanson DB, Grosso L, et al. A Comparison of knowledge, synthesis and clinical judgment. Multiple choice questions in the assessment of physician competence. Eval Health Prof 1984;7:485-99.

58 Norcini JJ, Swanson DB, Grosso L, et al. Reliability, validity and efficency of multiple choice questions and patient management problem item formats in the assessment of clinical competence. Med Educ 1985;19:238-47.

59 Driscoll P, Gwinnutt C, McNeill. Controversies in advanced trauma life support. J Trauma 1999;1:171-6.

60 Ali J, Gana TJ, Howard M. Trauma mannequin assessment of management skills of surgical residents after advanced life support training. J Surg Res 2000;93:197-200.

61 Marshall RI, Smith JS, Gorman PJ, et al. Use of a human patient simulator in the development of resident trauma management skills. J Trauma 2001;51:17-21.

62 Pendleton D, Schofield T, Tate $\mathrm{P}$, et al. The consultation: an approach to learning and teaching. Oxford: Oxford University Press, 2001

63 Daloz L. Effective teaching and mentoring. San Francisco: Jossey Bass, 1986

64 Ali J, Cohen R, Adam R, et al. Attrition of cognitive and trauma management skills after the advanced trauma life support (ATLS) course. J Trauma 1996:40:860-6.

65 Blumenfeld A, Ben-Abraham R, Stein M, et al. Cognitive knowledge and decline after advanced trauma life support courses. J Trauma 1998:44:513-16

66 Ali J, Howard M, Williams J. Is attrition of Advanced Trauma Life Support acquired skills affected by patient volume. Am J Surg 2002;183:142-5.

67 Ali J, Howard M, Williams J. Do factors other than trauma volume affect attrition of ATLS acquired skills? J Trauma 2003;54:835-41. 
68 Ali J, Adam R, Pierre I, et al. Comparison of performance 2 years after the old and new (interactive) ATLS courses. J Surg Res 2001;97:71-5.

69 Azcona A, Gutierrez GE, Fernandez CJ, et al. Attrition of advanced life support (ATLS) skills among ATLS instructors and providers in Mexico. J Am Coll Surg 2002; 195:372-7.

70 Bell RM, Krantz BE, Weigelt JA. ATLS: a foundation for trauma training. Ann Emerg Med 1999;34:233-7.
71 Heale J, Davis D, Norman G et al. A randomised controlled trial assessing the impact of problem based versus didactic teaching methods in CME. Proc Annu Conf Res Med Educ 1988;27:72-7.

72 Bligh D. What's the use of lectures? 6th ed. Bristol: Intellect, 2002.

73 Ali J, Adam RU, Josa D, et al. Comparison of performance of interns completing the old (1993) and new interactive (1997) Advanced Trauma Life Support Courses. J Trauma 1999;46:80-6.

\section{Clinical Evidence-Call for contributors}

Clinical Evidence is a regularly updated evidence-based journal available worldwide both as a paper version and on the internet. Clinical Evidence needs to recruit a number of new contributors. Contributors are healthcare professionals or epidemiologists with experience in evidence-based medicine and the ability to write in a concise and structured way.

Areas for which we are currently seeking authors:

- Child health: nocturnal enuresis

- Eye disorders: bacterial conjunctivitis

- Male health: prostate cancer (metastatic)

- Women's health: pre-menstrual syndrome; pyelonephritis in non-pregnant women

However, we are always looking for others, so do not let this list discourage you.

\section{Being a contributor involves:}

- Selecting from a validated, screened search (performed by in-house Information Specialists) epidemiologically sound studies for inclusion.

- Documenting your decisions about which studies to include on an inclusion and exclusion form, which we keep on file.

- Writing the text to a highly structured template (about 1500-3000 words), using evidence from the final studies chosen, within 8-10 weeks of receiving the literature search.

- Working with Clinical Evidence editors to ensure that the final text meets epidemiological and style standards.

- Updating the text every six months using any new, sound evidence that becomes available. The Clinical Evidence in-house team will conduct the searches for contributors; your task is simply to filter out high quality studies and incorporate them in the existing text.

- To expand the topic to include a new question about once every 12-18 months.

If you would like to become a contributor for Clinical Evidence or require more information about what this involves please send your contact details and a copy of your CV, clearly stating the clinical area you are interested in, to Klara Brunnhuber (kbrunnhuber@ bmigroup.com).

\section{Call for peer reviewers}

Clinical Evidence also needs to recruit a number of new peer reviewers specifically with an interest in the clinical areas stated above, and also others related to general practice. Peer reviewers are healthcare professionals or epidemiologists with experience in evidence-based medicine. As a peer reviewer you would be asked for your views on the clinical relevance, validity, and accessibility of specific topics within the journal, and their usefulness to the intended audience (international generalists and healthcare professionals, possibly with limited statistical knowledge). Topics are usually 1500-3000 words in length and we would ask you to review between 2-5 topics per year. The peer review process takes place throughout the year, and our turnaround time for each review is ideally 10-14 days.

If you are interested in becoming a peer reviewer for Clinical Evidence, please complete the peer review questionnaire at www.clinicalevidence.com or contact Klara Brunnhuber (kbrunnhuber@bmigroup.com). 